\title{
Habitat utilisation by the threatened Sichuan Partridge Arborophila rufipectus: consequences for managing newly protected areas in southern China
}

\author{
DAI BO, SIMON D. DOWELL, PETER J. GARSON and HE FEN-QI
}

\begin{abstract}
Summary
A number of former forest farms in southern Sichuan province, south-west China have been designated as protected areas following the 1998 logging ban in the upper Yangtze basin. These are within the range of the endemic Sichuan Partridge Arborophila rufipectus which has a fragmented distribution in the remnant broadleaf forests of this region, and is currently listed as 'Endangered' by IUCN. The design of a robust conservation plan for this species has been hampered by a lack of knowledge about its habitat preferences in a heavily modified environment. To remedy this, ranging behaviour and habitat utilization by this species was studied through a combination of a call count method and radio tracking of individual birds. The results indicate that A. rufipectus significantly prefers primary and older planted secondary broadleaf forest compared to forest degraded by human activity or scrub. Individual birds were found on the upper parts of slopes and made particular use of areas with a dense canopy and open understorey, whilst avoiding the lower slopes and areas close to trails where human disturbance is likely to be greater. The ongoing conservation programme for this partridge species is based on these findings and includes further protected area designations and management plans, the establishment of new forest corridors, and better control of hunting and other forms of forest exploitation.
\end{abstract}

\section{Introduction}

The conservation significance of the medium-altitude evergreen and deciduous broadleaf forests in south-central Sichuan has been highlighted by both BirdLife International for endemic birds (Stattersfield et al. 1997) and Conservation International (2007) as part of the Mountains of South-west China Biodiversity Hotspot. Yet before 1998, these ecosystems were largely ignored by the Chinese forestry authorities. Prior to this date, virtually all the remaining primary forest in this zone was divided into forest farms and destined for logging within a $20-40$ year period. Populations of surviving endemic birds, including the Sichuan Partridge Arborophila rufipectus, were therefore seriously threatened and their long-term survival seemed to be in doubt (King and Li 1988, Dai et al. 1998, Dowell et al. 1999). Following catastrophic floods on the Yangtze River in 1998, the Chinese Government introduced the National Forest Protection Programme, which included a moratorium on deforestation in the upper Yangtze basin and a change in land management policies that favoured soil and watershed protection (Liao 1999). This presented an opportunity to introduce better plans and action for biodiversity conservation, and a number of former Forest Farms (i.e. timber-production areas) have since been designated as protected areas. These reserves often include secondary and plantation woodland alongside surviving fragments 
of primary forest and a current challenge is to find ways to manage these areas for the benefit of their threatened and endemic wild species.

The Sichuan Partridge is one such endemic, restricted in its global distribution to evergreen and deciduous broadleaf forests at 1,100-2,250 m a.s.l. in southern Sichuan Province (Johnsgard 1988). BirdLife International (2007) currently categorises this species as 'Endangered' under the Red List criteria (IUCN 2001), on the grounds that it has a declining population of fewer than 2,500 mature individuals and occupies a highly fragmented habitat, with no single subpopulation exceeding 250 individuals (criterion EN C2a[i]). Its geographical range overlaps extensively with those of four other restricted range bird species: Gold-fronted Fulvetta Alcippe variegaticeps, Omei Shan Liocichla Liocichla omeiensis, Silver Oriole Oriolus mellianus and Emei Leaf Warbler Phylloscopus emeiensis. Consequently, this area of China falls within an Endemic Bird Area (Di4, Chinese Subtropical Forests), as defined by BirdLife International (Stattersfield et al. 1997).

The moratorium on deforestation has lessened the immediate threat of habitat destruction, although the long-term survival of the partridge in a highly fragmented forest landscape remains uncertain. Additional threats affecting this species arise from long traditions of livestock browsing, and bamboo shoot and medicinal plant collection, all of which have the potential to cause significant disturbance to the birds or their forest floor habitats, especially during the spring breeding period (Dowell et al. 1999). Despite having first class protection status in China (Zheng and Wang 1998), this species is also hunted, together with other species of Galliformes such as Temminck's Tragopan Tragopan temminckii and Silver Pheasant Lophura nycthemera with which it shares its habitats (Dai et al. 1998). Managers of new forest reserves require detailed information on the habitat requirements of endemic species like the Sichuan Partridge in order to reduce these threats effectively.

Until recently there were only anecdotal descriptions of the natural history of the Sichuan Partridge (Li et al. 1974, Li and Zhang 1992), although recent studies have described its calls (Liao et al. 2007b) and roosting behaviour (Liao et al. 2008). The possibility that there were more localities holding the species still to be discovered prompted a series of surveys in various habitat types in the 1990s. As a result, Dai et al. (1998) found several new populations and established that calling males in spring sometimes occupy secondary broadleaf forests at comparable densities to those found in primary forest, although they were apparently absent from conifer plantations. However, the forest landscape in this region is a fine-grained mosaic of these and other habitat types, and there remained a suspicion that the presence of individual birds might depend on close proximity to at least some primary forest (Xu et al. 1994).

Thus it became important to determine the extent to which individual Sichuan Partridges actually use the different habitats available to them, and a project of this sort was given international priority in the IUCN Action Plan for the partridges and their allies (Fuller et al. 2000). A study during the non-breeding season established that in winter, the birds prefer southfacing slopes in forest areas with limited bamboo cover (Liao et al. 2007c). A further study by the same authors established that the adult birds roost $1.7-6.4 \mathrm{~m}$ off the ground in dense shrub vegetation though away from bamboo thickets (Liao et al. 2008). The work reported here is the first attempt to describe the ranging behaviour of individual Sichuan Partridges during the breeding season, with the primary aim of determining their habitat preferences amongst components of the forest habitat mosaic, so that management of newly protected areas can be designed to favour this species. Conclusions derived from this analysis are translated into management guidelines for adoption in new protected areas harbouring significant populations of this species.

\section{Study Area}

In early 2000, an area of $11.07 \mathrm{~km}^{2}$ within the boundaries of Forest Farm No. 213 in Leibo County, southern Sichuan $\left(28^{\circ} 20^{\prime} 24^{\prime \prime} \mathrm{N}\right.$ to $28^{\circ} 22^{\prime} 19^{\prime \prime} \mathrm{N}$ and $103^{\circ} 29^{\prime} 16^{\prime \prime} \mathrm{E}$ to $\left.103^{\circ} 32^{\prime} 25^{\prime \prime} \mathrm{E}\right)$ was demarcated as the study site (Figure 1 ). It covers an altitudinal range of $1,280-2,000 \mathrm{~m}$ a.s.l. and 


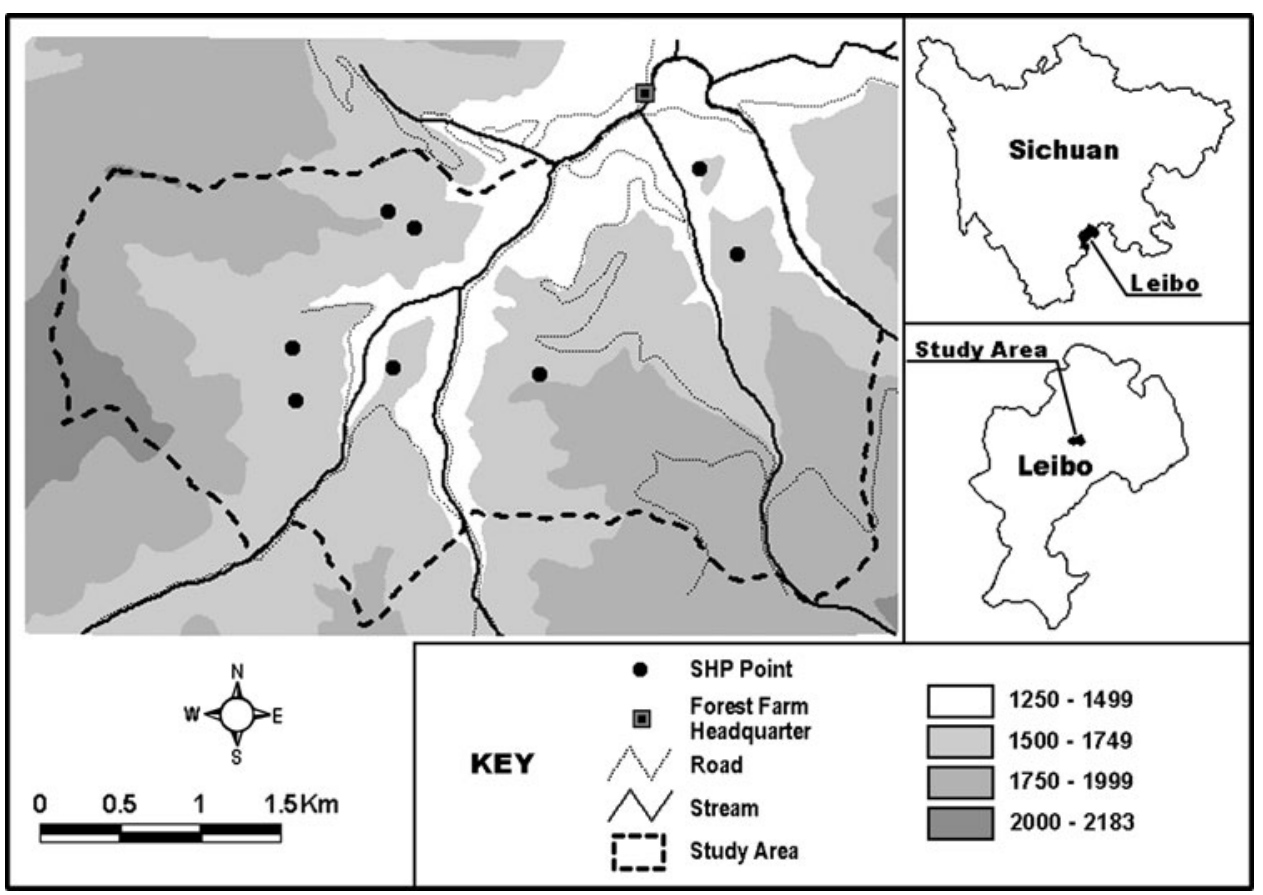

Figure 1. Map showing topography of the Sichuan Partridge study site at Forest Farm 213 in Leibo County, Sichuan Province, including insets indicating its location within Leibo County and in Sichuan Province, China.

lies on the northern slope of Jinping mountain, in the Daliang range. The climate is wet subtropical to temperate, with high precipitation (mean $1,421 \mathrm{~mm}$ per year) and relative humidity (mean $85 \%$ ). Temperatures are sub-zero for $2-3$ months in the winter at higher altitudes, but average temperatures exceed $25^{\circ} \mathrm{C}$ between June and August.

The natural vegetation in this area is evergreen broadleaf forest (Yang and Li 1992), dominated by species in the families Fagaceae, Lauraceae, Daphniphyllaceae, Ericaceae, with additional deciduous species of Aceraceae, Hippocastinaceae, Nyssaceae, Staphylaceae, Araliaceae and Corylaceae. Since the Forest Farm was set up for timber production in the early 1970 , $52 \%$ of the natural forest has been removed, and some land has been converted to agricultural use, especially on lower slopes and in valley bottoms. However, prior to the 1998 logging moratorium, most of the areas logged were replanted with faster growing local native broadleaf species, such as Sorbus folgneri and Pterostyrax psilophyllus, using seedlings grown at a nursery on site. A smaller area was also planted with coniferous species such as Cryptomeria fortunei and Cunninghamia lanceolata. This replanting has resulted in a current mosaic of forest blocks dating from 1972 to the present day. Some areas left for natural regeneration are dominated by pioneering scrub species such as Rubus spp. and bamboo. Older areas of this kind have gone through a natural succession to form a secondary forest habitat dominated by tree species commonly found in surviving primary forest patches.

Bamboo is a widespread understorey plant in all areas, with Chimonobambusa pachystachys dominant up to about $1,600 \mathrm{~m}$ and Qiongzhuea tumidinoda mainly occurring above this altitude. The ground vegetation is generally sparse and features species of the genera Diplazium, Polystichum, Pilea, Polygonum, Impatiens, Oxalis, Cardamine, Bidens, Carex, Paris, Liriope and Iris. Due to a long history of livestock browsing and fuel wood collection by local people in this 
region, some areas of the primary, replanted and naturally regenerated forest have been degraded into sparse woodland or scrub.

\section{Methods}

\section{Data collection}

From late February to late July 2000, dawn and dusk call monitoring was carried out daily by walking slowly along abandoned forestry roads and narrow trails in the study area and listening for the distinctive territorial calls given by males (Liao et al. 2007c). Calling by male Sichuan Partridge was concentrated in the first four hours after dawn (c. 05h3o) and from 16hoo until just before darkness (c. 2ohoo). Calling males were repeatedly located by taking two or more compass bearings from an array of 23 fixed reference points. GPS coordinates for these calling points were obtained later, in order to avoid disturbing the birds.

Birds were live-trapped for radio-tracking using snares made of sports racket twine or thick fishing line during March to May 2000 (under licence issued by the Wildlife Conservation Department of the Chinese Ministry of Forestry [now the State Forestry Administration]). Great care was taken to minimise the risk of damage to birds when snaring them. Snare-loops were lightly sprung on bent bamboo stems driven securely into the ground nearby, and triggered automatically when a bird disturbed the loose loop. All snares were checked at hourly intervals whenever they were set. Despite setting more than 100 snares in clusters at places known to be frequented by calling male partridges, only three males were caught and fitted with necklace transmitters (type TW-4, Biotrack, UK).

Once the radios were fitted, directional fixes were taken using a Mariner 57 Biotag receiver. The position of each tagged bird was determined once or twice a day by triangulation from at least three of the known reference points within a maximum of 1o minutes. This regime was maintained for as long as the radios were active or the birds remained alive.

Major habitat types were classified as primary broadleaf, old replanted broadleaf ( $15-28$ years old), young replanted broadleaf $(<15$ years old), planted conifer (all ages), degraded forest (primary and replanted), scrub, cultivation, tree nursery and open meadow. Their respective areas were calculated from a digitised habitat map of the whole study area (Table 1 ). The arithmetic mean centre of each calling male's radio- and call-fixes was calculated and a circle representing the area of a male's home range (see Results) was constructed around it. These areas were then used to determine the habitat utilisation pattern for each bird by overlaying them onto the digital habitat map, and computing the proportions of the major habitat types within each circle (using ArcView 3.2).

During a later visit to each point at which a bird was located from calls or radio signals, the microhabitat conditions were assessed within a radius of $20 \mathrm{~m}$ (0.13 ha). This was considered to be

Table 1. Habitat cover in the Sichuan Partridge study area within Forest Farm No. 213, Leibo County, Sichuan Province.

\begin{tabular}{lc}
\hline Habitat type & Area (ha) \\
\hline Primary broadleaf forest & 523 \\
Old replanted broadleaf forest & 345 \\
Young replanted broadleaf forest & 123 \\
Planted coniferous forest & 3 \\
Scrub & 31 \\
Degraded forest & 12 \\
Cultivated land & 51 \\
Tree nursery & 3 \\
Open herbs/Grass & 18 \\
Total & 1,109 \\
\hline
\end{tabular}


a suitable representation of the habitat around the location of the bird given the relative homogeneity of the habitat. A set of 53 fixes from all the birds together was obtained for further analysis after excluding a small number within $50 \mathrm{~m}$ of others, in an effort to ensure the spatial independence of points contributed by each bird. The following parameters were recorded at each point: aspect (in degrees away from due south), slope, altitude, position on slope (ridge, upper, middle, lower), micro-topography (gully, slope, ridge), presence of trail (yes or no), percentage cover for the canopy, shrub and ground vegetation layers (by eye), dominant bamboo species (Chimonobambusa pachystachys or Qiongzhuea tumidinoda) and density (high, medium, low), presence or absence of disturbance (livestock browsing, bamboo shoot collection, timber harvesting and firewood collection). The numbers of large trees (girth over $20 \mathrm{~cm}$ ) and small trees (girth $20 \mathrm{~cm}$ or less) were counted separately, and the 1o trees nearest to each point were checked for their species, girth, height and status (live, dead).

To allow microhabitat preferences to be detected, an equivalent set of 57 random points were visited within the study area. These were selected using random numbers to specify the coordinates of $125 \times 125 \mathrm{~m}$ grid squares overlaid on a map of the study area $(>750$ squares in all). The sample points were taken as the centre of the chosen squares and the same measurements were taken as for points at which birds had been detected.

\section{Data Analysis}

The positions of all calling birds detected repeatedly during dawn/dusk call monitoring were mapped to show tight clusters of points. Each of these was taken to represent a different territorial male, allowing their density to be estimated. For the determination of home range areas, limitations were applied as set by Kenward and Hodder (1996) on the use of RANGES (Version 5) in relation to numbers of fixes available per bird. Kenward and Hodder (1996) have argued that ellipses often require just $8-10$ fixes to give a stable index of range area while at least $15-20$ fixes are needed for density contouring procedures such as tail-weighting kernel. Polygon peeling requires larger samples of fixes and minimum convex polygons (MCPs) are typically stable after 30 fixes. So, for bird MI with eight fixes, the ellipse technique was used, while tail-weighting kernel analysis was adopted for bird $\mathrm{M}_{2}$ with 21 fixes. MCPs were taken for home range estimation of bird $\mathrm{M}_{3}$ for which we had 46 fixes.

To detect habitat preferences, the proportions of the major habitat types within the estimated home range of each male were compared with habitat proportions available in the whole study area (Table 1 ). The study area was selected for this purpose as it represented a discrete forest area within a water catchment, bordered by high ridges, known to be occupied by a population of Sichuan Partridges. Thus theoretically, all forest within the study area was available to the Sichuan Partridges. Compositional analysis (Aebischer et al. 1993) was used to assess the statistical significance of any selection for or avoidance of the different major habitat types, and to rank them in order of preference.

Microhabitat characteristics that were significantly related to the presence or absence of the partridge were identified using a binary logistic regression analysis, comparing parameter values at points where partridges were located $(n=53)$ with those at a random set of points $(n=57)$ distributed throughout the study area. Logistic regression was used in favour of other models (e.g. Discriminant Function Analysis) because the independent variables were a mixture of continuous (e.g. altitude), discrete (e.g. position on slope) and dichotomous (e.g. presence/absence of trail) variables.

\section{Results}

\section{Population census and home range}

Males calling from different points at the same time were treated as separate individuals, and points formed discrete clusters when mapped (Figure 2). The radio-fixes on the three tagged 


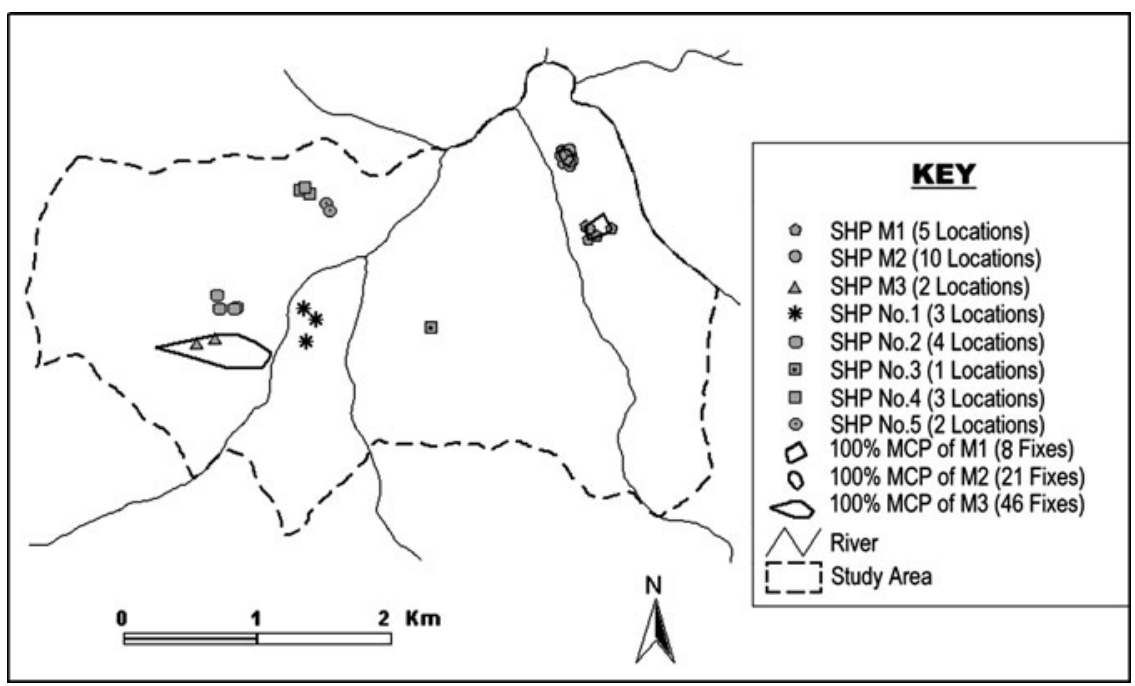

Figure 2. Central locations of eight individual male Sichuan Partridges at Forest Farm 213, Leibo County, Sichuan during March-July 200o. Three males were radio tagged and for these MCP home ranges are shown based on the radio fixes obtained $(8,21$ and 46 fixes respectively for the three tagged birds). A further five males were recorded from consistent calls (calling on at least three separate occasions) and the location of these are shown.

males could be overlaid precisely onto three of the clusters of call-fixes, making it obvious that these two data sets were from the same three birds, and validating the call-fix method for mapping the ranges of calling males, and thereby estimating their abundance. In all, a total of eight calling males were located in discrete localities in the study area (the three radio tagged birds and five others), yielding a density of 0.72 males $\mathrm{km}^{-2}$.

One radio-tagged male (MI) was predated by a Sparrowhawk Accipiter nisus within four days of being equipped, so that only eight fixes were obtained after its release (Table 2). A second bird (M2) was predated by a Spotted Linsang Prionodon pardicolor, but 21 fixes were obtained from this bird over eight days between tagging and predation. The third bird $\left(\mathrm{M}_{3}\right)$ was tracked continuously from 20 May to 5 July and 46 fixes were accumulated. Under the strictures recommended by Kenward and Hodder (1996) in relation to the sample size of fixes per bird, an ellipse was fitted to the data from $\mathrm{M}_{1}$, a tail-weighted kernel for $\mathrm{M}_{2}$, and a convex polygon with kernel fix for $\mathrm{M}_{3}$.

The home range estimates for individuals $\mathrm{M}_{1}$ and $\mathrm{M}_{3}$ are about an order of magnitude greater than that for M2 (Table 2). Direct observations indicated that M2 was unpaired, whilst

Table 2. Home range estimates (ha) computed by different procedures according to sample size for three male radio-tagged Sichuan Partridges (for full rationale see data analysis section of text. See Figure 2 for locations).

\begin{tabular}{lcll}
\hline Bird identity no. & $\mathrm{M}_{1}$ & $\mathrm{M}_{2}$ & $\mathrm{M}_{3}$ \\
\hline No. of Fixes & 8 & 21 & 46 \\
Using 100\% of fixes & 10.7 & 1.32 & 13.1 \\
Using 85\% of fixes & 4.40 & 1.02 & $9.51^{*}$ \\
& & Tail-weighting & Convex \\
Procedure & Ellipse & Kernel & Polygon with Kernel Fix \\
\hline
\end{tabular}

${ }^{*}$ This value was used to define circular utilised areas in the habitat preference analysis. 
$M_{1}$ and $M_{3}$ were often seen with a female, and $M_{3}$ was observed later with a female and one chick.

\section{Habitat use}

The area of the $85 \%$ convex polygon for the individual $M_{3}$ (9.51 ha) was taken as the value for constructing circles (of radius $174 \mathrm{~m}$ ) around the geometric centres of all eight males' ranges, to generate figures representing the pattern of habitat utilisation by each of them. A multivariate test for non-randomness shows that habitat selection by all the males together (data from all eight males combined) in relation to availability across the study area as a whole is significantly non-random (Wilk's lambda $=0.059, \chi_{3}^{2}=22.7, P<0.05$ ). Five of the habitat types did not occur within the areas around any of the eight range centres: young replanted broadleaf, planted conifer, cultivation, tree nursery and open herbs/grass. These habitats were therefore excluded from the compositional analysis. A sign matrix resulting from the compositional analysis (Table 3) allows the remaining four habitat types to be ranked and indicates that primary broadleaf and old planted broadleaf are utilised more with respect to their availability, compared to degraded forest and scrub which are utilised less. There is no significant difference between the utilisation of primary broadleaf over old planted broadleaf.

This lack of a significant difference between use of primary over replanted forest is confirmed on examination of the habitat associations of the individual radio-fixes for the bird yielding the most data. The distribution of radio-fixes for individual $\mathrm{M}_{3}$ across the habitats present within its home range ( $85 \%$ of fixes) shows that $15.22 \%$ were located in primary broadleaf and $84.78 \%$ in old replanted broadleaf, compared to respective availabilities of $10.36 \%$ and $89.64 \%$. For this individual, therefore, there was also no significant difference between habitat utilisation and availability in respect of these two habitats $\left(\chi_{1}^{2}=1.17, P=0.28\right)$. Unfortunately there was insufficient data from the other two radio-tagged individuals for a similar analysis.

The binary logistic regression analysis employed to detect any microhabitat preferences produced a statistically significant model $\left(\chi_{11}^{2}=95.7, P<0.001\right)$ identifying a set of eight variables as the best combination of predictors for presence or absence (Table $4 ; 90 \%$ of points correctly classified). Inspection of the coefficients indicates that locations with high canopy cover on the upper part of slopes or a ridge, and with medium or low bamboo cover, were most preferred by the birds. Conversely, the locations most avoided were at high altitude, with high ground cover and densities of large and small trees, lying close to a trail.

\section{Discussion}

This study has provided information on territorial male density and habitat requirements of the threatened Sichuan Partridge for use when drawing up management plans for new forest reserves

Table 3. Sign matrix for habitat preferences shown by eight male Sichuan Partridges in spring.

\begin{tabular}{llllll}
\hline \multicolumn{5}{l}{ Major Habitat Types: } \\
\cline { 2 - 6 } & $\begin{array}{l}\text { Primary } \\
\text { Broadleaf Forest }\end{array}$ & $\begin{array}{l}\text { Old Replanted } \\
\text { Broadleaf Forest }\end{array}$ & Scrub & $\begin{array}{l}\text { Degraded } \\
\text { Forest }\end{array}$ & Rank \\
\hline Primary Broadleaf Forest & & + & ++ & ++ & 3 \\
Old Replanted Broadleaf Forest & - & & ++ & + & 2 \\
Scrub & -- & -- & & - & 0 \\
Degraded Forest & -- & - & + & & 1 \\
\hline
\end{tabular}

,$+-=$ Habitat type in row is selected $(+$ )or avoided $(-)$ relative to habitat type in column;,++-represent statistically significant selection/avoidance (t-test $P<0.05$ ). 
Table 4. Forward stepwise binary logistic regression for habitat variables at Sichuan Partridge locations $(n=53)$ and random locations $(n=57)$.

\begin{tabular}{llccr}
\hline Step & Variable & Coefficient & df & $P$ \\
\hline 1 & Canopy cover & 17.9 & 1 & $<$ 0.001 \\
2 & Ground cover & -7.14 & 1 & $<0.001$ \\
3 & Altitude & -0.02 & 1 & 0.001 \\
4 & Position on slope & & 3 & 0.009 \\
& Ridge & 4.51 & 1 & 0.006 \\
& Upper & 5.55 & 1 & 0.002 \\
& Middle & 1.72 & 1 & 0.321 \\
5 & No. of large trees & -0.09 & 1 & 0.001 \\
6 & Presence of trail & -2.64 & 1 & 0.004 \\
7 & Bamboo density & & 2 & 0.016 \\
& Medium & 2.42 & 1 & 0.011 \\
8 & Low & 3.77 & 1 & 0.013 \\
& No. of small trees & -0.03 & 1 & 0.020 \\
& Constant & 31.6 & 1 & 0.001 \\
\hline
\end{tabular}

within its range. Although conclusions are based on a small sample size, this is the first time data have been collected on habitat utilisation during the breeding season.

The density of calling males estimated from this study is comparable to other estimates obtained from line transect data over a wider area by Dai et al. (1998). Xu et al. (1994) obtained figures of 2.75 males $\mathrm{km}^{-2}$ in primary forest and 0.75 males $\mathrm{km}^{-2}$ in secondary habitats at Huanglianshan, but subsequent visits by others have noted a catastrophic decline at this site, most of which has now been replanted with non-native conifers (Dai et al. 1998). As Xu et al. (1994) did not give details of their survey methods, it is not possible to compare their estimates directly with those obtained subsequently. However the strong inference that one of the three males radio-tagged in this study was unpaired implies that using calling male numbers may lead to an overestimate of the density of breeding pairs.

This study fell short of its objective to radio-tag at least ten individuals, so that a really robust assessment of home range use could be made to determine habitat preferences (Aebischer et al. 1993). In addition, two of the three tagged individuals were predated within eight days, raising the question of whether tagging itself increased predation risk. However, by using data from non-tagged territorial calling males in addition to data from the tagged individuals, it was possible to carry out a surrogate analysis of habitat preferences.

In the context of future conservation action, the findings to emphasise from this study are that the resident birds showed no significant preference for primary broadleaf over old planted broadleaf, and that these habitats were preferred to all others represented in the study area. The same result was obtained from an analysis of habitat preference for the one individual that was radio-tracked for a significant period of time in this study. Degraded forest and scrub, which are the result of over-exploitation for fodder and firewood by local people, were used significantly less by the birds than the two most preferred habitats, whilst young planted broadleaf was not used at all. These findings from our intensive study where individuals were followed throughout the breeding season confirm those of a previous extensive study which showed that calling male densities in areas dominated by primary and planted broadleaf forest were statistically indistinguishable in two successive years of surveys across a number of sites (Dai et al. 1998). This is important, as future attempts to expand the population of this species in and around nature reserves will rely on appropriate forest replanting schemes.

However, as it was not possible to assess breeding productivity in these two types of forest, no judgement can be made on whether old replanted forest provides an adequate alternative breeding habitat to primary forest. It might merely be acting as a sink habitat and therefore be of 
more limited utility. Proximity to primary forest could be measured in future surveys to determine the extent to which this bird relies on the continued presence of primary forest for its survival. Ideally, further work is required on this bird's breeding biology, though its elusive nature will make this difficult to achieve.

The analysis of microhabitat use in this study provides additional, more detailed data on habitat use during the breeding season which was previously unknown. This suggests that during the breeding season, Sichuan Partridges prefer areas containing a dense canopy with sparse cover and low bamboo density in the understorey layer. This is similar to habitat preferences found during the winter in Liao et al's (2007b) study, although they also found the birds at lower elevations $(1,000-1,600 \mathrm{~m})$ and closer to roads/paths and forest edges. In this study, the partridges significantly avoided trails and paths which may reflect more secretive habits during the nesting season. Our overall conclusion is that during the breeding season, this partridge prefers localities that are away from sources of direct disturbance, have a closed tree canopy and sparse cover at or near ground level. These conditions will facilitate their predominant foraging habit of searching for food in the damp leaf litter layer on the forest floor (MacKinnon et al. 200o). A preference for upper slopes, away from the disturbed valley bottoms as well as trails, suggests a significant aversion to direct human disturbance. These findings conflict with those of Li et al. (1974) who suggested that this species occupied areas of dense bamboo and shrubs in broadleaf forest. However, their assessment of habitat was based on the general features of areas occupied by the partridge rather than systematic searches of areas where birds were known to be living. In addition, Li et al. (1974) made their observations at a time when the species was probably much more numerous and widespread, therefore possibly occupying sub-optimal habitats in some places.

Our findings compare favourably with the study by Liao et al. (2008) of roosting behaviour, as they found that Sichuan Partridge roost sites have poorly-developed bamboo compared to randomly selected sites, although they also reported that their birds roosted in areas with a heavier shrub cover. Indeed, they found that the adult birds selected only six species of trees and shrubs in which to roost (and especially one, Eurya loquiana) even though these represented only $7.2 \%$ of the species available in the forest as a whole. Although we have confirmed that the birds can live in secondary and replanted forest, it will be important to ensure that future planting schemes include preferred roost tree species in order to provide favourable conditions for the Sichuan Partridge.

Although the planted broadleaf forest in our study area, and at similar sites nearby, is composed of only two to five dominant tree species, it matures quickly and appears to resemble primary forest in structure after only $15-20$ years. Thus for the long term benefit of the Sichuan Partridge, remaining areas of primary forest should, whenever possible, be linked by corridors of planted broadleaf forest. Conifers should not be used in such replanting schemes, and as many native broadleaf species as possible should be included, especially favoured roost trees like Eurya loquiana (Liao et al. 2008). This management policy should provide the means for substantially increasing the total area of habitat available for this species, thereby allowing for population growth, as well as the potential for gene flow between major sub-populations, through dispersal along the planted corridors.

The extent to which the habitat requirements recorded in this study are typical of other species in the genus Arborophila is difficult to determine as there have been few studies of similar species. A study of Chestnut-bellied Partridges A. javanica in Java, however, found that this species only seems able to survive in natural forest and it was more common in the interior of forests than around the edges (Nijman 2003). Altitude seemed to be the main determinant of the species' presence or absence, though the results were based on extensive surveys so did not examine habitat use at the micro level.

A study of Hill Partridges A. torqueola during the breeding season at Baiposhan Reserve in Sichuan, China, examined the habitat characteristics of sites from which birds were flushed and found that, like Sichuan Partridges in our study, Hill Partridges significantly preferred areas with 
greater tree cover and less bamboo (Liao et al. 2007a). They also found, however, that Hill Partridges mainly utilised sites that were close to roads, which conflicts with our findings showing that Sichuan Partridges avoid human trails. The Sichuan Partridge's more secretive behaviour may be due to hunting pressure in the Daliang Shan, driving birds away from human disturbance. Although illegal, hunting is a traditional activity in the Daliang Shan region and the hunting methods used, such as snares and traps, are effective in catching all galliform species of a similar size. The effect of hunting on the population size and density of Sichuan Partridge is not known. It is difficult to control poaching in remote forests, though recently, poaching patrols and protection of Sichuan Partridges at Laojunshan Nature Reserve has led to the birds becoming less fearful of humans, even nesting alongside the trail in 2007 (pers. obs.).

The accumulated survey and research work carried out on the Sichuan Partridge since 1996 has been used to inform the location, establishment and management of new protected areas after the national logging ban and changes in forestry policy in 1998. Three of these protected areas harbour populations of at least four of the five endemic bird species present in the area (Dowell and Dai 2003). The first of these at Laojunshan $\left(35 \mathrm{~km}^{2}\right)$ was designated as a Local Nature Reserve in 2000, becoming a Provincial Nature Reserve in 2002. There are plans to re-connect a number of remnant patches of primary forest in its western extension by planting corridors of broadleaf forest like that found at Forest Farm 213 during this intensive study. Preliminary surveys suggest that there is a population of over 100 pairs of Sichuan Partridge at Laojunshan. The second new protected area at Mamize $\left(380 \mathrm{~km}^{2}\right)$ includes substantial areas of primary broadleaf forest: it was designated as a Local Nature Reserve in 2001, and promoted to provincial status in 2003. Sichuan Partridges have been recorded in one part of the reserve, but detailed surveys have yet to be completed. The third area, established in 2004, is at Heizhugou and covers over $60 \mathrm{~km}^{2}$. This also contains Sichuan Partridge, although no population survey has yet been carried out.

Together, these three reserves are thought to protect a significant proportion of the remaining habitat of the Sichuan Partridge together with endemic passerines such as Omei Shan Liocichla and Gold-fronted Fulvetta. Further research is urgently needed on these passerines and others that depend on this habitat in order to determine their habitat requirements and find out whether these are compatible with those of the Sichuan Partridge in order to inform the future management of the reserves. Generally, though, bird populations in these three areas should all benefit from measures now being taken by the Sichuan Forestry Department to reduce the level of hunting and other forms of human disturbance. These involve the policing of entry points and control of livestock grazing, the collection of fuel wood and medicinal plant harvesting in the core areas, especially in the spring when breeding is in progress. Nevertheless, the widespread and illegal hunting of wildlife in this region needs to be controlled if this partridge is to survive anywhere other than within protected areas.

\section{Acknowledgements}

Work on the Sichuan Partridge was initiated and has been supported throughout by the World Pheasant Association. This study was funded through a Wildlife Conservation Training Fellowship for DB (1998-2000), awarded to PJG and SDD by the Wellcome Trust (UK). DB thanks his colleagues in the Sichuan Forestry Department, and local officials in the Leibo Forestry Bureau for their support and assistance in the field, especially Zhang Rongbo, Pu Daping, He Zhiguo, Zhang Wei, Li Jian and Yuan Lin. Substantial funding for the development of the new reserves has since been received from the North of England Zoological Society at Chester Zoo and from James Goodhart. We are grateful to Dr. Roger Wilkinson from Chester Zoo for facilitating and supporting the new reserves. The authors are indebted to Phil McGowan and Dave Lee whose comments and suggestions helped improve the manuscript. Two anonymous reviewers made further suggestions and improvements. 


\section{References}

Aebischer, N. J., Robertson, P. A. and Kenward, R. E. (1993) Compositional analysis of habitat use from animal radio-tracking data. Ecology 74: 1313-1325.

BirdLife International (2007). [http://www. birdlife.org/datazone/species/index.html? action $=$ SpcHTMDetails. aspandsid $=214$ andm $=0$, accessed 16 March 2007].

Conservation International (2007) [http:// www.biodiversityhotspots.org/xp/Hotspots/ china/, accessed 16 March 2007].

Dai Bo, Dowell, S. D., Martins, R. P. and Williams, R. S. R. (1998) Conservation status of the Sichuan Hill-partridge Arborophila rufipectus in China. Bird Conserv. Internatn. 8: 349-359.

Dowell, S. D., Dai, B., Martins, R. P. and Williams, R. S. R. (1999) Sustainable management to prevent extinction: the case of the Sichuan Hill-partridge Arborophila rufipectus. Pp. 2084-2096 in N. J. Adams and R. H. Slotow, eds. Proceedings of the 22nd International Ornithological Congress. Johannesburg: BirdLife South Africa.

Dowell, S. D. and Dai Bo (2003) A conservation breakthrough in Sichuan. World Birdwatch 25: 22-25.

Fuller, R. A., Carroll, J. P. and McGowan, P. J. K., eds. (2000) Partridges, quails, francolins, snowcocks, guineafowl and turkeys: status survey and conservation action plan 2000-2004. Gland, Switzerland and Cambridge, UK: IUCN and the World Pheasant Association.

IUCN (2001) IUCN Red List categories and criteria. Version 3.1. Gland, Switzerland and Cambridge, UK: IUCN, Species Survival Commission. [http://www.iucn.org/themes/ ssc/redlists/RLcats2001booklet.html]

Johnsgard, P. A. (1988) The quails, partridges and francolins of the world. Oxford, UK: Oxford University Press.

Kenward, R. E. and Hodder, K. H. (1996) RANGES $V$ manual. Furzebrook, Dorset, UK: Institute of Terrestrial Ecology.

King, B. and Li, Gui-yuan (1988) China's most endangered galliform. Oryx 22: 216217.

Li, Gui-yuan and Qing-mao, Zhang (1992) The nests, eggs and calls of the Sichuan
Hill-partridge (Arborophila rufipectus). Acta Zool. Sinica 38: 108-109. (In Chinese).

Li, Gui-yuan, Liu, Liang-cai, Zhang, Rui-yun and Zhang, Qing-mao (1974) Discovery of the female of the Sichuan Hill-partridge. Acta Zool. Sinica2O: 421-422. (In Chinese).

Liao, W. B., Hu, J. C. and Li, C. (2007a) Habitat utilization during the pairing season by the Common Hill-partridge Arborophila torqueola in Baiposhan Natural Reserve, Sichuan, China. Orn. Sci. 6: 8794.

Liao, W. B., Li, C., Hu, J. C. and Lu, X. $(2007 \mathrm{~b})$ Habitat utilization of the Sichuan Hill-partridge (Arborophila rufipectus) in the non-breeding period in Laojunshan Nature Reserve. Zool. Res. 28: 167-171.

Liao, W. B., Li, C., Hu, J. C. and Lu, X. (2007c) Vocal behaviour of Sichuan Hill-partridge (Arborophila rufipectus) in breeding season. Zool. Res. 28: 56-62. (In Chinese with English abstract).

Liao, W. B., Hu, J. C., Li, C. and Lu, X. (2008) Roosting behaviour of the endangered Sichuan Hill-partridge Arborophila rufipectus during the breeding season. Bird Conserv. Internatn. 18: 260-266.

Liao, Y. H. (1999) Rebuilt the Green Great Wall-report from the stop-logging areas in West Sichuan. Decision and Information 173: 4-5.

MacKinnon, J., Phillipps, K. and He, Fen-qi (2000) A field guide to the birds of China. Oxford, UK: Oxford University Press.

Nijman, V. (2003) Distribution, habitat use and conservation of the endemic Chestnutbellied Hill-partridge (Arborophila javanica) in fragmented forests of Java, Indonesia. Ети 103: 133-140.

Stattersfield, A. J., Crosby, M. J., Long, A. J. and Wege, D. C. (1997). Endemic Bird Areas of the world: priorities for biodiversity conservation. Cambridge, UK: BirdLife International.

Xu, Zhao-hui., Mei, Wen-zheng, Zhang, Gang, Chen, Xin-hua and Zeng, Zhaoqun (1994) Observations on the wintering habits of the Sichuan hill-partridge. Chinese J. Zool. 29: 21-23. (In Chinese with English abstract). 
Yang, Yu-po and Li, Cheng-biao, eds. (1992) Forests in Sichuan. Beijing, China: China Forestry Publishing House. (In Chinese).
Zheng, G. and Wang, Q. (1998) China Red Data Book of endangered animals: Aves. Beijing: Science Press.

\section{DAI BO}

College of Life Sciences, Sichuan University, Chengdu, 610064, P.R. China.

SIMON D. DOWELL*

School of Natural Sciences and Psychology, Liverpool John Moores University, Byrom Street, Liverpool L3 $3 A F$, U.K.

\section{PETER J. GARSON}

School of Biology, Ridley Building, Newcastle University, Newcastle upon Tyne NEI $7 R U$, U.K.

\section{HE FEN-QI}

Institute of Zoology, Chinese Academy of Sciences, 25 Beisihuan Xi Lu, Beijing 10oo8o, China.

${ }^{*}$ Author for correspondence; e-mail: s.d.dowell@livjm.ac.uk

Received 23 October 2007; revision accepted 7 July 2008 